\title{
Into the abyss: diabetes process of care indicators and outcomes of defaulters from a Canadian tertiary care multidisciplinary diabetes clinic
}

\author{
Janine C Malcolm ${ }^{1,2,9^{*}}$, Julie Maranger ${ }^{2,3 \dagger}$, Monica Taljaard ${ }^{3,4 \dagger}$, Baiju Shah ${ }^{5,6,10 \dagger}$, Chetna Tailor ${ }^{1 \dagger}$, Clare Liddy ${ }^{1,7,8,9 \dagger}$,
} Erin Keely ${ }^{1,2,9+}$ and Teik Chye Ooi ${ }^{1,2,9}$

\begin{abstract}
Background: Continuity of care is essential for good quality diabetes management. We recently found that $46 \%$ of patients defaulted from care (had no contact with the clinic for 18 months after a follow-up appointment was ordered) in a Canadian multidisciplinary tertiary care diabetes clinic. The primary aim was to compare characteristics, diabetes processes of care, and outcomes from referral to within 1 year after leaving clinic or to the end of the follow-up period among those patients who defaulted, were discharged or were retained in the clinic.

Methods: Retrospective cohort study of 193 patients referred to the Foustanellas Endocrine and Diabetes Center (FEDC) for type 2 diabetes from January 1, 2005 to June 30, 2005. The FEDC is the primary academic referral centre for the Ottawa Region and provides multidisciplinary diabetes management. Defaulters (mean age $58.5 \pm 12.5$ year, $60 \% \mathrm{M}$ ) were compared to patients who were retained in the clinic (mean age $61.4 \pm 10.47$ years, 49\% M) and those who were formally discharged (mean age $61.5 \pm 13.2$ years, $53.3 \% \mathrm{M}$ ). The chart audit population was then individually linked on an individual patient basis for laboratory testing, physician visits billed through OHIP, hospitalizations and emergency room visits using Ontario health card numbers to health administrative data from the Ministry of Health and Long-Term Care at the Institute for Clinical and Evaluative Sciences (ICES).

Results: Retained and defaulted patients had significantly longer duration of diabetes, more microvascular complications, were more likely to be on insulin and less likely to have a HbA1c $<7.0 \%$ than patients discharged from clinic. A significantly lower proportion of patients who defaulted from tertiary care received recommended monitoring for their diabetes (HbA1c measurements, lipid measurements, and periodic eye examinations), despite no difference in median number of visits to a primary care provider (PCP). Emergency room visits were numerically higher in the defaulters group.
\end{abstract}

Conclusions: Patients defaulting from a tertiary care diabetes hospital do not receive the recommended monitoring for their diabetes management despite attending PCP appointments. Efforts should be made to minimize defaulting in this group of individuals.

\section{Background}

The importance of continuity of care in diabetes management has been well recognized. Continued attendance at multidisciplinary diabetes management programs has been shown to decrease the risk of long-term diabetes complications [1-4], improve the uptake of preventive

\footnotetext{
* Correspondence: jamalcolm@ottawahospital.on.ca

'Equal contributors

'Department of Medicine, University of Ottawa, Ottawa, ON, Canada

${ }^{2}$ The Ottawa Hospital Research Institute, Ottawa, ON, Canada

Full list of author information is available at the end of the article
}

care, enhance adherence to therapy, increase patient and physician satisfaction [5] and decrease hospitalizations [6] and emergency room visits [7-9]. Despite these benefits, high rates of attrition and loss to follow-up have been reported [10-12]. Defaulting from diabetes clinics may be defined as the failure of a patient to maintain contact with the clinic despite a scheduled follow-up appointment made by the specialist. Defaulting from diabetes clinics is associated with adverse outcomes including the development of significant microvascular disease, worsening of biochemical profile and all-cause mortality [13].

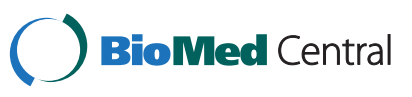


The effect of defaulters on health care utilization is likely significant. Patient care may be negatively impacted by large numbers of patients requiring re-referral for specialized services. Re-referral rates for defaulted patients with diabetes to specialized care have been reported to be as high as $20 \%$ [10]. Among elderly patients with diabetes, loss of continuity of care is associated with increased hospitalizations and emergency room visits [6]. To date, studies on patients defaulting from specialty diabetes clinics have focused primarily on clinical outcomes. Understanding the health care utilization of diabetes patients defaulting from specialty care is important in developing strategies to improve continuity of care for patients with type 2 diabetes (DM2).

A local audit of our tertiary care multidisciplinary clinic indicated that $23 \%$ of patients referred by primary care providers for diabetes care were discharged back to primary care, while $46 \%$ of patients defaulted from clinic [14]. We suspect that the extent of defaulting observed in our centre may be reflective of other tertiary care diabetes clinics.

In this paper, we describe the characteristics, longterm outcomes, and health care utilization of patients who defaulted from clinic and compare them to those who were retained or were discharged back to the care of their primary care provider.

\section{Methods}

The Foustanellas Endocrine and Diabetes Centre (FEDC) in Ottawa, Canada is the academic referral centre for the Ottawa region. It serves a catchment area of over one million people and provides specialized interdisciplinary clinical management, education and self-management support for diabetes. There are approximately 20,000 patient visits per year, of which $20 \%$ are new referrals.

A chart audit was conducted at the FEDC by an endocrinology fellow and a diabetes nurse specialist. The first 10 charts were reviewed independently by both auditors and the results compared. A data collection guide was developed based on discrepancies between the two auditors. The remainder of the charts was divided between the two auditors and data were entered electronically into the database using the data collection guide. The auditors met on a regular basis to review items for which interpretation remained unclear after using the data collection guide.

The chart audit population was then individually linked using Ontario health card numbers to health administrative data from the Ministry of Health and LongTerm Care housed at the Institute for Clinical and Evaluative Sciences (ICES). Because of the single-payer universal health care system in Ontario, these data describe all care received by Ontario residents with no missing data or loss to follow-up. The databases used in this study included: the Registered Persons Database, which records health care eligibility and demographic information such as date of death; the discharge abstract database for hospital admission information occurring after the date of final recorded visit with the FEDC during the review period; the National Ambulatory Care Reporting System for emergency department visits occurring after the last recorded visit with the FEDC during the review period; the physician service claims database for family doctor and specialist visits, laboratory tests and renal replacement therapy; and the ICES Physicians Database for location and type of physician practice.

Laboratory investigations done at the Ottawa Hospital were in the OACIS Ottawa Hospital Database. This database was searched by the investigators for all pertinent laboratory results done in the follow-up period for all three groups.

All patients who were first seen by an endocrinologist for management of DM2 between January 1 and June 30, 2005 were included in a retrospective chart review. Of the 923 referred diabetes patients, 226 were excluded due to a clear diagnosis of type 1 diabetes (DM1). A computer-generated, uniform random number was assigned to the remaining 697 patients who were then assessed for eligibility in random sequence until the targeted sample size of 200 was reached. The sample size of 200 was chosen to allow a two-sided 95\% Confidence Interval (CI) for a single proportion (e.g., the proportion of patients discharged from the clinic), using the large sample normal approximation, to extend $7.1 \%$ from the most conservative proportion of $50 \%$, while allowing for a $5 \%$ patient exclusion rate.

Data collected in the FEDC chart review included: demographics, past medical history, medication use, processes of care indicators, outcome of care indicators, number of visits to each diabetes team member (physician, nurse, dietician, social worker), and current status with FEDC (discharged back to PCP, retained, or defaulted). Defaulting was defined as no contact with the clinic for 18 months after a follow-up appointment was ordered by the specialist. Data collection continued until the patient was discharged or had defaulted or until the end of the follow-up period in October 2008, whichever came first.

Individuals were then linked between databases and across time via their Ontario health card number, anonymized using a reproducible encryption algorithm. Processes of care indicators (percent receiving A1c measurements, lipid profiles, serum creatinine, annual eye examination), health care utilization (mean visits to primary care physician) and outcomes (emergency room visits and hospital admissions) were collected. 
Demographic information, and first and last visit data information was compared among the three groups. The proportions of patients meeting the 2003 Canadian Diabetes Association (CDA) recommended targets (CDA guidelines) for glycated hemoglobin (A1C $\leq 7 \%$, LDL cholesterol $<2.5 \mathrm{mmol} / \mathrm{L}$, and blood pressure $\leq 130 / 80$ were calculated ; the proportions of patients meeting one, two or all three targets were compared among the groups. This study was developed prior to the publication of the 2013 CDA guidelines, at which point some of the targets changed. The 2003 guidelines differ from the 2013 guidelines in a few minor areas. The glycated hemoglobin target remained $\leq 7 \%$ for most patients with type 1 and type 2 diabetes; however the 2013 guidelines allow for greater individualization of targets for patients based on their age, duration of diabetes, risk of severe hypoglycaemia, life expectancy, and presence cardiovascular disease. The LDL-cholesterol target has dropped to $<2.0 \mathrm{mmol} / \mathrm{L}$ based on evidence from a number of large randomized controlled trials published after 2003. The blood pressure targets remained the same. As these changes were minor, the difference in guidelines from 2003 to 2013 does not have a significant effect the interpretation of the results.

This study was approved by the Ottawa Hospital Research Ethics Board.

\section{Statistical analysis}

Using chart review data, the demographic characteristics and first and last visit outcomes of the patient cohort were summarized for defaulters retained and discharged groups. Frequencies and percentages were calculated for categorical variables, means and standard deviations for continuous variables, and medians and interquartile ranges (IQR) for ordinal variables or variables with skewed distributions. Differences in process and clinical outcome measures among the three groups (retained, discharged, and defaulted) were tested for statistical significance using 1-way analysis of variance in the case of continuous variables, chi-squared tests or Fisher's exact tests for categorical variables, and Kruskal-Wallis tests for ordinal variables or variables with skewed distributions. Because we recognize that multiple testing can lead to spurious statistical significance, we considered all these tests as exploratory. If the overall test among the three groups was significant at $\alpha=0.15$, we proceeded to conduct pairwise tests to further delineate differences between the groups. To maintain the familywise error rate of the pairwise comparisons, the Bonferronicorrected significance level of $\alpha=0.017$ was used for these pairwise comparisons. It was expected that some proportion of the items would be incomplete in this chart review. For example, we only recorded retinopathy as present or absent if a test for retinopathy had been indicated in the chart; if no test result were available, this item was recorded as missing. No imputation for missing items was planned; each analysis was based on subjects with non-missing values for the relevant variables.

Using the linked health administrative data, dichotomous process of care, and outcomes of defaulters, the retained and discharged groups were described using point estimates with 95\% confidence intervals for proportions using the normal approximation to the binomial distribution, or the exact binomial method in the case of small frequencies.

Outcomes summarized as counts (e.g., number of visits with primary care providers, or number of $\mathrm{HbA1C}$ measurements) were described as annual rates, together with 95\% Poisson confidence intervals using exact methods or using the normal approximation with continuity correction.

The statistical significance of differences in process of care, and proximal and distal outcomes among the three patient groups were assessed using chi-squared tests for dichotomous variables and one-way analysis of variance for continuous variables.

All analyses were conducted using SAS version 9.1 (Cary, NC).

\section{Results}

Of the original 200 patients, one chart was noted to be entered twice during statistical analysis and was excluded. Of the remaining 199 patients, 2 patients had died and 4 were transferred to another institution. These patients, making up only $3.1 \%$ of the total cohort, are not included in further description and analysis. The characteristics of the remaining 193 patients at their first visit to the FEDC are presented in Table 1. Referred patients had a median duration of diabetes of 6 years (IQR $1-12)$, and lived primarily in an urban setting (90.2\%). Macrovascular complications were present in 51 patients $(28.3 \%)$ and 79 patients $(40.9 \%)$ had microvascular complications.

Of the 193 patients, $29.6 \%$ (95\% CI 24.1\%-37.1\%) were retained in clinic (after a median duration of follow-up of 33 months), 23.1\% (95\% CI 17.8\%-29.9\%) were discharged (after a median duration of follow-up of 10 months), and 44.2\% (95\% CI 38.6\%-52.6\%) defaulted (after a median duration of follow-up of 9 months).

When these 3 groups were examined retrospectively to their first visit at the FEDC (see Table 1), duration of diabetes, proportion of re-referrals, proportion of patients with any microvascular disease, neuropathy, insulin use, and $\mathrm{HbA} 1 \mathrm{c} \leq 7 \%(53 \mathrm{mmol} / \mathrm{mol})$, were significantly different among the three groups based on the overall test of significance. Based on the pairwise comparisons, the retained group had longer duration of 
Table 1 Comparison of first visit characteristics among patients retained, discharged, and defaulted

\begin{tabular}{|c|c|c|c|c|c|c|c|c|}
\hline First visit characteristics & $\begin{array}{l}\text { Overall } \\
(\mathrm{N}=193)\end{array}$ & $\begin{array}{l}\text { Retained } \\
\text { (R) }(\mathrm{N}=59)\end{array}$ & $\begin{array}{l}\text { Discharged } \\
(D / C)(N=46)\end{array}$ & $\begin{array}{l}\text { Defaulted } \\
\text { (DF) (N=88) }\end{array}$ & $\begin{array}{l}\text { Over all } \\
\mathrm{p} \text {-value }\end{array}$ & $\begin{array}{l}\text { R vs. } \\
\text { D/C }\end{array}$ & $\begin{array}{l}\text { R vs. } \\
\text { DF }\end{array}$ & $\begin{array}{l}\text { D/C vs. } \\
\text { DF }\end{array}$ \\
\hline Age (mean, SD) & $59.1(12.3)$ & $59.1(9.9)$ & $60.6(14)$ & $58.3(12.9)$ & 0.5944 & & & \\
\hline Male (\%) & $106(54.9)$ & $28(47.5)$ & $25(54.4)$ & $53(60.2)$ & 0.3112 & & & \\
\hline Distance from clinic (km)(median, IQR) & $12.4(7.4-20.5)$ & $14.2(7.9-20.7)$ & $13.4(7.2-17.8)$ & $10.7(7.5-23.9)$ & 0.7194 & & & \\
\hline Urban (\%) & $174(90.2)$ & $51(86.4)$ & $45(97.8)$ & 78 (88.6) & 0.1227 & 0.0741 & 0.6906 & 0.0967 \\
\hline Number of re-referrals (\%) & $36(18.8)$ & $14(24.1 \%)$ & $3(6.5 \%)$ & $19(21.6 \%)$ & 0.0477 & 0.0158 & 0.7188 & 0.0254 \\
\hline \multicolumn{9}{|l|}{ Medical history } \\
\hline Duration DM2 (years) - (median, IQR) & $6(1-12)$ & $8(2-15)$ & $2.5(1-8.5)$ & $7(2.5-12)$ & 0.0187 & 0.0146 & 0.7622 & 0.0114 \\
\hline Hypertension (\%) & $142(74)$ & $44(74.6)$ & $34(75.6)$ & $64(72.7)$ & 0.9321 & & & \\
\hline Dyslipidemia (\%) & $154(83.7)$ & $49(86.0)$ & $36(83.7)$ & $69(82.1)$ & 0.8338 & & & \\
\hline Psychiatric disease (\%) & $41(21.9)$ & $16(27.6)$ & $7(15.6)$ & $18(21.4)$ & 0.3388 & & & \\
\hline \multicolumn{9}{|l|}{ Macrovascular complications } \\
\hline CAD (\%) & $41(22.5)$ & $16(28.6)$ & $8(18.2)$ & $17(20.7)$ & 0.4066 & & & \\
\hline PVD (\%) & $11(6.0)$ & $5(8.5)$ & $1(2.3)$ & $5(6.1)$ & 0.5275 & & & \\
\hline CVA/TIA (\%) & $10(5.3)$ & $6(10.2)$ & 0 & $4(4.7)$ & 0.0719 & 0.0380 & 0.3170 & 0.3005 \\
\hline Any macrovascular complications (\%) & $51(28.3)$ & $21(36.8)$ & $8(18.6)$ & $22(27.5)$ & 0.1311 & 0.0466 & 0.2455 & 0.2733 \\
\hline \multicolumn{9}{|l|}{ Microvascular complications } \\
\hline Nephropathy (\%) & $49(27.1)$ & $18(31.6)$ & $9(20.9)$ & $22(27.2)$ & 0.4945 & & & \\
\hline Retinopathy (\%) & $26(17.6)$ & $12(23.5)$ & $2(5.9)$ & $12(19.1)$ & 0.1026 & 0.0316 & 0.5595 & 0.1281 \\
\hline Neuropathy (\%) & $49(26.9)$ & $13(22.4)$ & $7(16.3)$ & $29(35.8)$ & 0.0424 & 0.4443 & 0.0901 & 0.0226 \\
\hline Any microvascular complications (\%) & $79(40.9)$ & $24(47.1)$ & $13(33.3)$ & $42(59.2)$ & 0.0328 & 0.1897 & 0.1860 & 0.0096 \\
\hline \multicolumn{9}{|l|}{ Disease status } \\
\hline HbA1c (\%)(mean, SD) & $8.5(1.9)$ & $8.6(1.8)$ & $7.9(1.9)$ & $8.7(1.9)$ & 0.0609 & 0.0669 & 0.6694 & 0.0243 \\
\hline $\mathrm{HbA1c}$ (IFCC units $\mathrm{mmol} / \mathrm{mol}$ ) & 69 & 70 & 63 & 72 & & & & \\
\hline $\mathrm{HbA} 1 \mathrm{c} \leq 7.0 \%$ or $53 \mathrm{mmol} / \mathrm{mol}(\%)$ & $47(25.5)$ & $16(27.6)$ & $17(39.5)$ & $14(16.9)$ & 0.0199 & 0.2055 & 0.1259 & 0.0051 \\
\hline Weight (kg) (mean, SD) & $94.1(23.2)$ & $93.0(22.3)$ & $88.9(18.9)$ & $97.6(25.3)$ & 0.1122 & 0.3252 & 0.2608 & 0.0448 \\
\hline BMI (mean, SD) & $33.8(7.7)$ & $33.8(7.8)$ & $32.5(6.3)$ & $34.5(8.2)$ & 0.3738 & & & \\
\hline SBP (mean, SD) & $140.9(20.0)$ & $141.2(23.2)$ & $138.7(19.3)$ & $141.8(18.0)$ & 0.6879 & & & \\
\hline DBP (mean, SD) & $75.1(10.0)$ & $75.5(11.1)$ & $75.4(9.4)$ & $74.6(9.5)$ & 0.8267 & & & \\
\hline Total Cholesterol (mean, SD) & $4.99(1.41)$ & $4.96(1.44)$ & $4.98(1.1)$ & $5.02(1.55)$ & 0.9694 & & & \\
\hline HDL-C (mean, SD) & $1.19(0.33)$ & $1.22(0.32)$ & $1.21(0.33)$ & $1.15(0.33)$ & 0.5015 & & & \\
\hline LDL-C (mean, SD) & $2.65(1.01)$ & $2.64(1.04)$ & $2.85(1.03)$ & $2.53(0.97)$ & 0.3139 & & & \\
\hline Triglycerides (median, IQR) & $2.06(1.5-2.92)$ & $1.92(1.39-2.99)$ & $2.12(1.58-2.59)$ & $2.18(1.5-2.99)$ & 0.8033 & & & \\
\hline TC:HDL-C (mean, SD) & $4.33(1.41)$ & $4.19(1.27)$ & $4.35(1.27)$ & $4.43(1.59)$ & 0.6311 & & & \\
\hline Smoker (\%) & $37(20.1 \%)$ & $8(13.8)$ & $7(16.3)$ & $22(26.5)$ & 0.1390 & 0.7283 & 0.0695 & 0.1960 \\
\hline \multicolumn{9}{|l|}{ First visit medications } \\
\hline On Insulin (\%) & $47(24.4 \%)$ & $23(39.0)$ & $3(6.5)$ & $21(23.9)$ & 0.0006 & 0.0001 & 0.0498 & 0.0129 \\
\hline On ACE-I/ARB (\%) & $114(59.7)$ & $44(74.6)$ & $25(54.4)$ & $45(52.3)$ & 0.0191 & 0.0303 & 0.0069 & 0.8245 \\
\hline On ASA (\%) & 76 (39.8) & $26(44.1)$ & 16 (35.6) & $34(39.1)$ & 0.6684 & & & \\
\hline On Statin (\%) & $98(50.8)$ & $34(57.6)$ & $23(50.0)$ & $41(46.6)$ & 0.4198 & & & \\
\hline
\end{tabular}

Note: $p$-values significant at $5 \%$, with Bonferroni adjustment for pairwise comparisons, are printed in bold type. $R$ Retained, $D / C$ Discharged, DF Defaulted, CAD Coronary artery disease, PVD Peripheral vascular disease, CVA Cerebral vascular accident, TIA Transient ischemic attack, HbA1c Glycated hemoglobin, $\mathrm{kg}$ kilograms, BMI Body mass index, SBP Systolic blood pressure, DBP Diastolic blood pressure, HDL-C High-density lipoprotein-cholesterol, TC:HDL-C Total cholesterol to HDL-cholesterol ratio, LDL-C Low-density lipoprotein-cholesterol, ACE-I Angiotensin-converting enzyme inhibitor, ARB Angiotensin receptor blocker (antagonist), ASA Acetylsalicylic acid, MD Medical doctor, RN Registered nurse, $R D$ Registered dietitian, SD Standard deviation, IQR Interquartile range. 
DM2, a higher proportion of re-referrals, and were more likely to be on insulin at baseline than the discharged group. Patients who had defaulted had longer duration of DM2, were more likely to have microvascular complications, were less likely to have $\mathrm{HbA} 1 \mathrm{c} \leq 7 \%$ and were more likely to be on insulin at baseline than those discharged. No difference was noted in mean distance travelled to the clinic or proportion living in an urban setting between groups.

A comparison of characteristics of the 3 groups at the last visit is presented in Table 2. Significant differences among the groups were found for the proportions of patients with any microvascular complications, retinopathy, and $\mathrm{HbA} 1 \mathrm{c} \leq 7 \%$. The proportions of patients on insulin and acetylsalicylic acid (ASA) at last visit were also significantly different among the groups with the highest proportion on these medications in the retained group. Based on the pairwise comparisons, patients who defaulted were more likely to be on insulin and less likely to have $\mathrm{HbA} 1 \mathrm{c} \leq 7 \%$ at last visit than discharged patients. Compared with those retained in the clinic, defaulted patients were less likely to be on insulin or ASA at last visit. No significant differences among the groups were noted for macrovascular complications, blood pressure, smoking status, LDL-C, use of angiotensin-converting enzyme inhibitor (ACE-I), angiotensin receptor blocker antagonist (ARB) and use of statins.

Significant differences were noted for indicators of clinic activity (Table 2). The mean percentage of visits where medications were changed by the physician was lowest in the discharged group (34.4\% versus $55.2 \%$ in the retained group and $51.8 \%$ in the defaulted group, $\mathrm{p}$ $=0.0007)$. The median percentage of missed appointments that were no-shows was highest in the defaulted group (30\% versus $8.3 \%$ in the retained group and $0 \%$ in the discharged group, $\mathrm{p}<0.0001$ ).

The percentages of patients meeting 2003 CDA Guideline recommended targets for $\mathrm{HbA1c}$, LDL-C and BP at their last clinic visit are presented in Figure 1. The defaulted group had the lowest proportion of patients meeting all three targets at $4.8 \%$. Of the patients who attained treatment targets for LDL-C and HbA1c, retained patients were more likely to be on insulin at their last clinic appointment (44.4\%) than those discharged (12.0\%) or defaulted (7.7\%) but these differences were not statistically significant at the Bonferronicorrected levels. There were no statistically significant differences in microvascular or macrovascular complications among groups in patients who had reached 2 or 3 targets at their last clinic visit.

Long-term outcomes of our cohort were available for 179 patients (Table 3). Patients without Ontario Health Card Numbers (e.g., residents of the neighbouring province of Quebec) $(\mathrm{N}=14)$ were excluded from this analysis. A significantly lower proportion of patients who defaulted from tertiary care received recommended monitoring for their diabetes (HbAlc measurements, lipid measurements, and periodic eye examinations), despite no difference in mean number of visits to a primary care provider (PCP). The proportion of patients with emergency room visits was numerically higher in the defaulters group.

\section{Discussion}

We found almost half of the patients referred to the clinic (44.2\%) defaulted from care, while $23.1 \%$ were discharged and $29.6 \%$ of patients were retained in clinic. Patients in the defaulted group had the lowest proportion reaching CDA treatment targets for HbA1c, LDL-C, and BP while attending diabetes clinic. One year after the last documented clinic appointment, the defaulted patient group also had the lowest proportion receiving A1C measurements, lipid profile measurements and eye examinations despite having a similar mean number of visits to primary care physicians as the discharged and retained patients groups. A possible explanation is primary care physicians may have been unaware that the patient had stopped attending diabetes clinic visits and were therefore not ordering diabetes monitoring investigations. Patients may also have perceived their diabetes as "less important" relative to their other medical problems and therefore did not follow through with recommended monitoring or the follow up with the diabetes clinic.

The long-term consequences of defaulting from a diabetes clinic such as worsened glucose control, increased $\mathrm{BP}$, increased prevalence of complications, and increased all cause mortality have been reported [13]. Currie et al. have demonstrated a "dose -response" relationship with those having $>2$ missed appointments being at significantly higher risk of all cause mortality. Decreased monitoring may increase the need for emergency treatment of acute decompensations. The proportion of patients with emergency room visits was numerically higher in our cohort. Access to specialty care may be negatively impacted if these patients require re-referral to already overstretched diabetes resources. Identification of patients at risk of defaulting is necessary to both prevent negative impact on the health care system and possibly prevent adverse outcomes for patients. One finding that may signal a patient at risk of defaulting is failure to keep appointments $[12,15]$. Consistent with other groups, we also observed that the no-show rate was highest in the defaulted population.

The high proportion of patients defaulting from care was initially surprising to us. This rate is, however, similar to other reports [16]. The prevalence of defaulting 
Table 2 Comparison of last visit characteristics among patients retained, discharged, and defaulted

\begin{tabular}{|c|c|c|c|c|c|c|c|c|}
\hline Last visit characteristics & $\begin{array}{l}\text { Overall } \\
(\mathrm{N}=193)\end{array}$ & $\begin{array}{l}\text { Retained } \\
(\mathrm{R})(\mathrm{N}=59)\end{array}$ & $\begin{array}{l}\text { Discharged } \\
(D / C)(N=46)\end{array}$ & $\begin{array}{l}\text { Defaulted } \\
\text { (DF) }(\mathrm{N}=88)\end{array}$ & $\begin{array}{l}\text { Overall } \\
\text { p-value }\end{array}$ & $\begin{array}{l}\text { R vs. } \\
\text { D/C }\end{array}$ & $\begin{array}{l}\text { R vs. } \\
\text { DF }\end{array}$ & $\begin{array}{l}\text { D/C vs. } \\
\text { DF }\end{array}$ \\
\hline \multicolumn{9}{|l|}{ Macrovascular complications } \\
\hline CAD (\%) & $45(23.8)$ & $17(29.3)$ & $9(20.0)$ & $19(22.1)$ & 0.4802 & & & \\
\hline PVD (\%) & $14(7.5)$ & $6(10.2)$ & $1(2.3)$ & $7(8.2)$ & 0.3081 & & & \\
\hline CVA/TIA (\%) & $12(6.3)$ & $7(12.1)$ & $1(2.2)$ & $4(4.6)$ & 0.1305 & 0.1336 & 0.1164 & 0.4980 \\
\hline Any macrovascular complications (\%) & $57(30.0)$ & $23(39.0)$ & $10(22.2)$ & $24(27.9)$ & 0.1539 & & & \\
\hline \multicolumn{9}{|l|}{ Microvascular complications } \\
\hline Nephropathy (\%) & $65(35.7)$ & $24(40.7)$ & $11(25.6)$ & $30(37.5)$ & 0.2635 & & & \\
\hline Retinopathy (\%) & $31(18.8)$ & $14(25.6)$ & $2(5.1)$ & $15(21.7)$ & 0.0406 & 0.0121 & 0.7080 & 0.0228 \\
\hline Neuropathy (\%) & $50(27.3)$ & $15(25.9)$ & $7(15.9)$ & $28(34.6)$ & 0.0785 & 0.2261 & 0.2735 & 0.0265 \\
\hline Any microvascular complications (\%) & $95(53.7)$ & $31(53.5)$ & $16(37.2)$ & $48(63.2)$ & 0.0243 & 0.1057 & 0.2576 & 0.0064 \\
\hline \multicolumn{9}{|l|}{ Disease status (last visit): } \\
\hline HbA1c (\%)(mean, SD) & $7.6(1.6)$ & $7.8(1.8)$ & $6.6(0.9)$ & $7.9(1.5)$ & $<0.0001$ & $<0.0001$ & 0.7069 & $<0.0001$ \\
\hline HbA1c (IFCC units mmol/mol) & 60 & 62 & 49 & 63 & & & & \\
\hline $\mathrm{HbA} 1 \mathrm{c} \leq 7.0 \%$ or $53 \mathrm{mmol} / \mathrm{mol}(\%)$ & $86(46.2)$ & $25(42.4)$ & $37(84.1)$ & $24(28.9)$ & $<0.0001$ & $<0.0001$ & 0.0964 & $<0.0001$ \\
\hline Change in $\mathrm{HbA} 1 \mathrm{c}(\%)$ (mean, SD) & $-0.90(1.7)$ & $-0.74(1.75)$ & $-1.28(1.87)$ & $-0.80(1.69)$ & 0.2480 & & & \\
\hline Weight (kg) (mean, SD) & $94.5(23.3)$ & $94.3(21.8)$ & $88.8(21.2)$ & $97.6(25.0)$ & 0.1289 & 0.2074 & 0.4183 & 0.0495 \\
\hline Change in weight (mean, SD) & $0.8(5.1)$ & $1.6(5.6)$ & $0.3(5.3)$ & $0.4(4.7)$ & 0.2978 & & & \\
\hline BMI & $33.9(7.7)$ & $34.2(7.4)$ & $32.5(7.2)$ & $34.5(8.2)$ & 0.3726 & & & \\
\hline $\mathrm{SBP}($ mean, SD) & $139.2(19.8)$ & $141.7(21.8)$ & $133.4(17.9)$ & $140.5(18.9)$ & 0.0712 & 0.0390 & 0.7263 & 0.0376 \\
\hline DBP (mean, SD) & $73.1(9.6)$ & $71.8(9.6)$ & $72.4(10.4)$ & $74.2(9.1)$ & 0.2828 & & & \\
\hline Total Chol (mean, SD) & $4.5(1.4)$ & $4.4(1.2)$ & $4.4(1.1)$ & $4.7(1.6)$ & 0.2377 & & & \\
\hline HDL-C (mean, SD) & $1.2(0.3)$ & $1.1(0.3)$ & $1.2(0.3)$ & $1.2(0.3)$ & 0.6053 & & & \\
\hline LDL-C (mean, SD) & $2.3(1.0)$ & $2.4(1.0)$ & $2.3(1.0)$ & $2.3(1.0)$ & 0.8984 & & & \\
\hline Triglycerides (median, QR) & $1.8(1.2-2.7)$ & $1.7(1.3-2.5)$ & $1.8(1.2-2.5)$ & $1.9(1.3-3.2)$ & 0.3467 & & & \\
\hline TC:HDL-C (mean, SD) & $4.1(1.4)$ & $4.03(1.2)$ & $3.82(1.2)$ & $4.31(1.6)$ & 0.1874 & & & \\
\hline Smoker (\%) & $33(18.8)$ & $6(10.9)$ & $7(16.3)$ & $20(25.6)$ & 0.0897 & 0.4367 & 0.0349 & 0.2365 \\
\hline \multicolumn{9}{|l|}{ Last visit medications: } \\
\hline On insulin (\%) & 75 (38.9) & $37(62.7)$ & $7(15.2)$ & $31(35.2)$ & $<0.0001$ & $<0.0001$ & 0.0011 & 0.0147 \\
\hline On ACE-I/ARB (\%) & $144(74.6)$ & $48(81.4)$ & $33(71.7)$ & $63(71.6)$ & 0.3604 & & & \\
\hline On ASA (\%) & $94(48.7)$ & $37(62.7)$ & $20(43.5)$ & $37(42.1)$ & 0.0351 & 0.0497 & 0.0140 & 0.8734 \\
\hline On Statin (\%) & $146(75.7)$ & $49(83.1)$ & $37(80.4)$ & $60(68.2)$ & 0.0825 & 0.7297 & 0.0436 & 0.1320 \\
\hline \multicolumn{9}{|l|}{ Clinic activity } \\
\hline Median duration of follow-up (months) & $16(6$ to 31$)$ & 33(31 to 35$)$ & 10 (4 to 18$)$ & $9(5$ to 17$)$ & $<0.0001$ & $<0.0001$ & $<0.0001$ & 0.8827 \\
\hline $\begin{array}{l}\% \text { of MD visits where meds changed } \\
\text { (Mean, SD) }\end{array}$ & $48.7(30.0)$ & $55.2(23.1)$ & $34.4(25.7)$ & $51.8(33.9)$ & 0.0007 & $<0.0001$ & 0.5037 & 0.0027 \\
\hline $\begin{array}{l}\% \text { of patient encounters that were } \\
\text { no-shows (Median, IQR) }\end{array}$ & 14.3 (0 to 33.3 ) & $8.3(0$ to 16.7$)$ & 0 (0 to 14.3$)$ & 30 (13.8 to 50.0$)$ & $<0.0001$ & 0.1112 & $<0.0001$ & $<0.0001$ \\
\hline Number of visits with MD (mean, SD) & $4.9(3.1)$ & $8.1(2.8)$ & $3.3(1.9)$ & $3.7(2.0)$ & $<0.0001$ & $<0.0001$ & $<0.0001$ & 0.2907 \\
\hline Number of visits with RN (mean, SD) & $2.5(2.1)$ & $3.7(2.6)$ & $2.1(1.7)$ & $2.0(1.7)$ & $<0.0001$ & 0.0006 & $<0.0001$ & 0.6919 \\
\hline Number of visits with RD (mean, SD) & $2.4(2.0)$ & $3.5(2.5)$ & $2.2(1.9)$ & $1.7(1.3)$ & $<0.0001$ & 0.0036 & $<0.0001$ & 0.1053 \\
\hline
\end{tabular}

Note: p-values significant at 5\%, with Bonferroni adjustment for pairwise comparisons, are printed in bold type, $R$ Retained, $D / C$ Discharged, $D F$ Defaulted, CAD Coronary artery disease, PVD Peripheral vascular disease, CVA Cerebral vascular accident, TIA Transient ischemic attack, HbA1c Glycated hemoglobin, $\mathrm{kg}$ kilograms, $B M I$ Body mass index, SBP Systolic blood pressure, DBP Diastolic blood pressure, HDL-C High-density lipoprotein-cholesterol, TC:HDL-C Total cholesterol to HDL-cholesterol ratio, LDL-C Low-density lipoprotein-cholesterol, ACE-I Angiotensin-converting enzyme inhibitor, ARB Angiotensin receptor blocker (antagonist), $A S A$ Acetylsalicylic acid, MD Medical doctor, $R N$ Registered nurse, $R D$ Registered dietitian, $S D$ Standard deviation, IQR Interquartile range. 


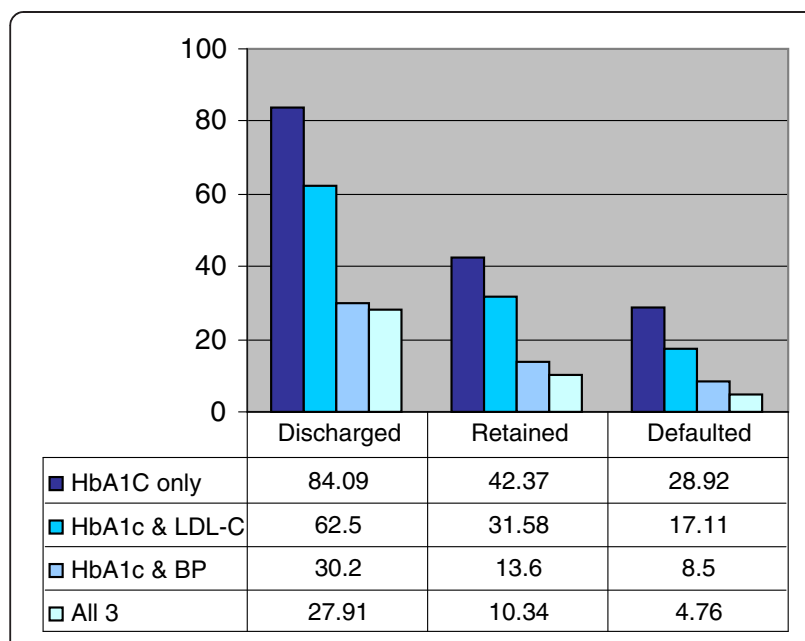

Figure 1 Percentage of patients in each group achieving 2003 Canadian Diabetes Association recommended targets for HbA1c, LDL-C and BP.

from diabetes clinics ranges from 4-19\% in Britain $[10,17-19], 12-50 \%$ in the United States [11,20], and 35$57 \%$ in Japan $[4,21]$. In Canada, there are little data on defaulting rates. Shah et al. [22] reported that among patients referred to endocrinologists at 4 Canadian teaching hospitals, $23.5 \%$ did not return for a follow-up visit after an initial visit with the endocrinologist.

Our review was not designed to identify reasons for defaulting; however, we have identified some trends. Defaulters had a numerically higher mean weight, and the highest proportion of smokers. These findings were similar to those of Graber et al. [11] and Currie et al. [13], who found that the proportion of smokers was significantly higher in patients who missed clinic appointments. This finding may be due in part to the challenges patients who default from specialty care face in the management of their disease. These patients are less likely to participate in self-care, are more likely to have denial concerning their disease and are likely less engaged and empowered in the management of their disease. It is therefore not surprising that we observed that the defaulters group had the lowest proportion of patients meeting targets for $\mathrm{HbA1c}$, BP, or LDL-C during the time they were followed in the diabetes clinic and were more likely to be on insulin than discharged patients. They had a similar percentage of visits where medications were changed by the attending physician to that of patients in the retained group [52\% vs. 55\%] suggesting unstable disease. These findings suggest that defaulters from our clinic had the most poorly controlled disease and should have had continued follow-up.

In contrast to our findings, Masuda et al. found defaulters were younger, less likely to be on medications, had shorter duration of diabetes, and lower HbA1c levels [23]. The authors concluded that these patients with "milder" disease may have been discharging themselves from clinic due to the belief that their disease was not severe enough to warrant intensive therapy. Simmons et al. and Currie et al. had similar results $[13,24]$. The differences between our population of defaulters and defaulters described by others likely reflect the referral pattern of our region in which the more complex patients with advanced disease are referred to tertiary care while patients with milder disease are cared for in the community. This finding may be similar to other communities with a similar referral structure.

It is also interesting to note that despite poor glycemic control, the percentage of patients on insulin at last visit with the FEDC was significantly lower in the defaulted group compared to the retained group. Some patients possibly chose not to return to clinic when insulin therapy was proposed. It is likely that patients who fail to achieve control because of inadequate adherence to behavioural change or medications are also likely to be inadherent with attending clinic [25].

The primary limitation of this study is the inherent nature of a chart audit. Patient records may be incomplete reflections of the care encounter. Lack of standardization in chart formats, variations in professional recording practices and legibility are also concerns [26].

Table 3 Comparison of process-of-care indicators and outcomes 1 year after study end

\begin{tabular}{|c|c|c|c|c|}
\hline Variable & Retained $\mathrm{N}=51$ & Discharged $\mathrm{N}=45$ & Defaulted $\mathrm{N}=83$ & P-value \\
\hline Mean A1c measurements received (sd) & $1.92(1.31)$ & $1.58(1.32)$ & $1.37(1.15)$ & 0.055 \\
\hline Received A1C (\%) & $46(90.2)$ & $33(73.3)$ & $56(67.5)$ & 0.011 \\
\hline Received lipid profile (\%) & $46(90.2)$ & $35(77.8)$ & $54(65.1)$ & 0.004 \\
\hline Received eye exam (\%) & $41(80.4)$ & $27(60.0)$ & $44(53.0)$ & 0.006 \\
\hline Received Creatinine (\%) & $45(88.2)$ & $37(82.2)$ & $62(74.7)$ & 0.15 \\
\hline Mean visits to primary care (sd) & $8(7)$ & $6.5(5)$ & $6.4(6)$ & 0.319 \\
\hline Received annual physical exam (\%) & $9(17.6)$ & $7(15.6)$ & $10(12)$ & 0.654 \\
\hline Proportion with an emergency room visit (\%) & $13(25.5)$ & $10(22.2)$ & $33(39.8)$ & 0.071 \\
\hline Proportion admitted to hospital (\%) & $9(17.6)$ & $6(13.3)$ & $18(21.7)$ & 0.501 \\
\hline
\end{tabular}


Although we did not have the resources to conduct double extraction of the data, measures were taken to ensure inter-rater reliability. A data extraction guide was created and frequent meetings between auditors were held to minimize problems in interpretation of data recorded. Our analyses excluded patients with missing values, and to the extent that patients with missing values are significantly different from those included in the analysis, our comparisons may be biased.

\section{Conclusions}

In our review of patients referred to an interdisciplinary clinic with DM2, we found a low discharge rate but a much higher than anticipated proportion of patients who defaulted from clinic. Patients who defaulted from clinic had the most uncontrolled disease and did not receive recommended monitoring of their diabetes after leaving the diabetes clinic despite continued visits to primary care. No show rates were highest in the defaulting population and could signal patients at risk of defaulting. Further study into the reasons, long-term consequences and strategies to prevent defaulting is required to ensure that this population receives the care they need.

\section{Competing interests}

The authors declare they have no competing interests.

\section{Authors' contributions}

JCM conceived of the study, participated in study design, interpretation of data, and drafted the manuscript. JM conceived of the study, participated in study design, interpretation of data, data collection, and drafted the manuscript. BS participated in study design and performed statistical analysis. MT participated in study design and performed statistical analysis. EK participated in study design and interpretation of data. $C T$ participated in study design, interpretation of data, data collection and helped to draft the manuscript. TO conceived of the study, participated in study design, interpretation of data and helped to draft the manuscript. CL participated in study design and was involved revising the manuscript. All authors read and approved the final manuscript.

\section{Acknowledgements \\ Unrestricted grants received from Novo Nordisk Canada Inc., LifeScan Canada Ltd., Merck Frosst Canada Ltd., Schering-Plough Canada Inc. and Merck Frosst/Schering Pharmaceuticals were used to fund this research. All phases of this study, including design, data collection, analysis and interpretation, report writing and decision to submit this article for publication were undertaken by the authors, independently from any funders.}

\section{Author details \\ ${ }^{1}$ Department of Medicine, University of Ottawa, Ottawa, ON, Canada. ${ }^{2}$ The Ottawa Hospital Research Institute, Ottawa, ON, Canada. ${ }^{3}$ Clinical Epidemiology Program, Ottawa Hospital Research institute, Ottawa, ON, Canada. ${ }^{4}$ Department of Epidemiology and Community Medicine, University of Ottawa, Ottawa, ON, Canada. ${ }^{5}$ Department of Medicine, University of Toronto, Toronto, Canada. ${ }^{6}$ Department of Medicine, Sunnybrook Health Sciences Centre, Toronto, ON, Canada. ${ }^{7}$ Bruyere Research Institute, Ottawa, ON, Canada. ${ }^{8}$ Department of Family Medicine, University of Ottawa, Ottawa, ON, Canada. ${ }^{9}$ The Ottawa Hospital, Ottawa, ON, Canada. ${ }^{10}$ Institute for Clinical Evaluative Sciences, Toronto, ON, Canada.}

Received: 11 February 2013 Accepted: 8 August 2013 Published: 10 August 2013

\section{References}

1. Holman RR, Paul SK, Bethel MA, Neil HA, Matthews DR: 10-Year follow-up of intensive glucose control in type 2 diabetes. New England Journal of Medicine 2008, 359:1577-1589.

2. Gaede P, Vedel P, Larsen N, Jensen GV, Parving HH, Pederson O: Multifactorial intervention and cardiovascular disease in patients with type 2 diabetes. New England Journal of Medicine 2003, 348:383-393.

3. Gaede P, Lund-Andersen H, Parving HH, Pederson O: Effect of a multifactorial intervention on mortality in type 2 diabetes. New England Journal of Medicine 2008, 358:580-591.

4. Sone H, Kawai K, Takagi H, Yamada N, Kobayashi M: Outcome of one-year of specialist care of patients with type 2 diabetes: a multi-center prospective survey. Intern Med 2006, 45:589-597.

5. Gray DP, Evans P, Sweeney K, Lings P, Seamark D, Dixon M, Bradley N: Towards a theory of continuity of care. Journal of Research of Social Medicine 2003, 96:160-166

6. Knight J, Dowden JJ, Worrall GJ, Gadag VG, Murphy MM: Does higher continuity of family physician care reduce hospitalizations in elderly people with diabetes? Popul Health Manag 2009, 12:81-86.

7. Gill JM, Mainous AG, Nsereko M: The effect of continuity of care on emergency department use. Arch Fam Med 2000, 9:333-338.

8. Ionescu-lttu R, McCusker J, Ciampi A, Vadeboncour AM, Roberge D, Larouche D, Verdon J, Pineault R: Continuity of primary care and emergency department utilization among elderly people. CMAJ 2007, 177:1362-1368.

9. McCusker J, Tousignant P, Borges Da Silva R, Ciampi A, Levesque JF, Vadeboncoeur A, Sanche S: Factors predicting patient use of the emergency department: a retrospective cohort study. CMAJ 2012, 184:E307-E316.

10. Archibald LK, Gill GV: Diabetic clinic defaulters - Who are they and why do they default? Practical Diabetes 1992, 9(1):13-14.

11. Graber AL, Davidson P, Brown AW, McRae JR, Woolridge K: Dropout and relapse during diabetes care. Diabetes Care 1992, 15:1477-1483.

12. Karter AJ, Parker MM, Moffett HH, Ahmed AT, Ferrara A, Liu JY, Selby JV: Missed appointments and poor glycemic control: an opportunity to identify high-risk diabetic patients. Med Care 2004, 42:110-115.

13. Currie CJ, Peyrot M, Morgan CL, Poole CD, Jenkins-Jones S, Rubin RR, Burton C, Evans M: The impact of treatment noncompliance on mortality in people with Type 2 Diabetes. Diabetes Care 2012, 35:1279-1284.

14. Tailor C, Malcolm J, Maranger J, Keely E, Brez S, Izzi S, Taljaard M, Ooi TC: He tools for transition program: characteristics and disposition of patients referred to a multi-disciplinary diabetes clinic. Canadian Journal of Diabetes 2008, 32(1):27.

15. Lee $\mathrm{V}$, Earnest $\mathrm{A}$, Chen $\mathrm{M}$, Krishnan B: Predictors of failed attendance in a multi-specialty outpatient centre using electronic databases. BMC Health Serv Res 2005, 5:1-8.

16. Gucciardi E: A systematic review of attrition from diabetes education services: strategies to improve attrition and retention research. Can J Diabetes 2008, 32:53-65.

17. Lloyd J, Sherriff R, Fisher M, Burns-Cox C: Non-attendance at the diabetes clinic. Practical Diabetes 1990, 7:228-229.

18. Hammersley MS, Holland MR, Walford S, Thorn PA: What happens to defaulters from a diabetes clinic? Br Med J 1985, 291:1330-1332.

19. Scobie I, Rafferty A, Franks P, Sonksen $\mathrm{H}$ : Why patients were lost to follow-up from an urban diabetic clinic. Br Med J 1983, 286:189-190.

20. Benoit S, Ji M, Flemming R, Philis-Tsimikas A: Predictors of dropouts from a San Diego diabetes program: a case control study. Prev Chronic Dis 2004, 1:1-8.

21. Kawahara R, Amemiya T, Yoshino M, Miyamae M, Sasamoto K: Dropout of young non-insulin-dependent diabetics from diabetes care. Diabetes Res Clin Pract 1994, 24:181-185.

22. Shah B, James J, Lawton C, Montada-Atin T, Sigmon M, Cauch-Dudek K, Booth G: Diabetes quality of care in academic endocrinology practice: a descriptive study. Can J Diabetes 2009, 33:150-155.

23. Masuda YA, Kubo A, Kokaze A, Yoshida M, Sekiguchi K, Fukuhara N, Takashima Y: Personal features and dropout from diabetes care. Environ Health Prev Med 2006, 11:115-119.

24. Simmons D, Flemming C: Prevalence and charactersitics of diabetic patients with no ongoing care in South Aukland. Diabtes Care 2000, 23:1791-1793. 
25. Rhee M, Slocum W, Zeimer DC, Culler SD, Cook CB, El-Kebbi IM, Gallina DL, Barnes C, Phillips LS: Patient adherence improves glycemic control. Diabetes Educ 2005, 31:240-250.

26. Jennett $P$, Affleck $L$ : Chart audit and chart simulated recall as methods of needs assessment in continuing professional health education. JCEHP 1998, 18:163-171.

doi:10.1186/1472-6963-13-303

Cite this article as: Malcolm et al.: Into the abyss: diabetes process of care indicators and outcomes of defaulters from a Canadian tertiary care multidisciplinary diabetes clinic. BMC Health Services Research 2013 13:303.

\section{Submit your next manuscript to BioMed Central and take full advantage of:}

- Convenient online submission

- Thorough peer review

- No space constraints or color figure charges

- Immediate publication on acceptance

- Inclusion in PubMed, CAS, Scopus and Google Scholar

- Research which is freely available for redistribution 